\title{
Spatial patterns of ecosystem vulnerability changes during 2001-2011 in the three-river source region of the Qinghai-Tibetan Plateau, China
}

\author{
GUO Bing ${ }^{1,2}$, ZHOU Yi ${ }^{1 *}$, ZHU Jinfeng ${ }^{1}$, LIU Wenliang ${ }^{1}$, WANG Futao ${ }^{1}$, WANG Litao ${ }^{1}$, \\ YAN Fuli ${ }^{1}$, WANG Feng ${ }^{1}$, YANG Guang ${ }^{1,2}$, LUO Wei ${ }^{1,2}$, JIANG Lin $^{1}$ \\ ${ }^{1}$ Institute of Remote Sensing and Digital Earth, Chinese Academy of Sciences, Beijing 100101, China; \\ ${ }^{2}$ University of Chinese Academy of Sciences, Beijing 100049, China
}

\begin{abstract}
The three-river source region (TRSR, including Yangtze, Yellow and Lancang rivers), located in the Qinghai-Tibetan Plateau, China, is a typical alpine zone with apparent ecosystem vulnerability and sensitivity. In this paper, we introduced many interdisciplinary factors, such as landscape pattern indices (Shannon diversity index and Shannon evenness index) and extreme climate factors (number of extreme high temperature days, number of extreme low temperature days, and number of extreme precipitation days), to establish a new model for evaluating the spatial patterns of ecosystem vulnerability changes in the TRSR. The change intensity $(\mathrm{Cl})$ of ecosystem vulnerability was also analyzed. The results showed that the established evaluation model was effective and the ecosystem vulnerability in the whole study area was intensive. During the study period of 2001-2011, there was a slight degradation in the eco-environmental quality. The Yellow River source region had the best eco-environmental quality, while the Yangtze River source region had the worst one. In addition, the zones dominated by deserts were the most severely deteriorated areas and the eco-environmental quality of the zones occupied by evergreen coniferous forests showed a better change. Furthermore, the larger the change rates of the climate factors (accumulative temperature of $\geq 10^{\circ} \mathrm{C}$ and annual average precipitation) are, the more intensive the $\mathrm{Cl}$ of ecosystem vulnerability is. This study would provide a scientific basis for the eco-environmental protection and restoration in the TRSR.
\end{abstract}

Keywords: eco-environmental vulnerability; climate factors; spatial patterns; three-river source region

Citation: GUO Bing, ZHOU Yi, ZHU Jinfeng, LIU Wenliang, WANG Futao, WANG Litao, YAN Fuli, WANG Feng, YANG Guang, LUO Wei, JIANG Lin. 2016. Spatial patterns of ecosystem vulnerability changes during 2001-2011 in the three-river source region of the Qinghai-Tibetan Plateau, China. Journal of Arid Land, 8(1): 23-35. doi: $10.1007 / \mathrm{s} 40333-015-0055-7$

Ecosystem vulnerability has become a serious environmental problem throughout the world. Rapid industrialization and urbanization have largely contributed to the eco-environmental deterioration (Goetz et al., 2005). During the past decades, global warming has brought significant effects on terrestrial ecosystems, and these effects are projected to be greater in the future (Fu et al., 2007; IPCC, 2007). Moreover, global warming has modified the disturbance regimes, altering the frequency, duration and intensity of ecological disturbance processes (Chapin et al., 2000; Goetz et al., 2005; Westerling et al., 2011). Unfortunately, the increasing rate of temperature change in the three-river source region (TRSR) of the Qinghai-Tibetan

*Corresponding author: ZHOU Yi (E-mail: Zhouyi@radi.ac.cn)

Received 2015-03-05; revised 2015-06-16; accepted 2015-06-29

(C) Xinjiang Institute of Ecology and Geography, Chinese Academy of Sciences, Science Press and Springer-Verlag Berlin Heidelberg 2016

http://jal.xjegi.com; www.springer.com/40333 
Plateau has obviously been greater than those in other regions of the world during the past decades (Li and Kang, 2006). Climate warming has brought large influence on soil quality and grassland productivity, and has resulted in some other serious desertification in the TRSR in recent decades (Liu et al., 2008). Furthermore, the alpine meadow grassland has suffered different degradation degrees in this region from both human beings and climate changes (Wang et al., 2011). Therefore, grassland degradation and land desertification have significantly altered the regional ecosystem and water cycle in the TRSR (Guo et al., 2002).

Eco-environmental evaluation was developed in the 1960s as a means of quantitatively and qualitatively assessing the environmental situation (Eisele et al., 2003). Eco-environmental evaluation can provide basic data and information for sustainable development in typical zones (Popp et al., 2000; Linder et al., 2010), such as urban areas (Ng and Obbard, 2005) and mountain zones (Eisele et al., 2003; Isidori et al., 2004). In recent years, considerable interests have focused on identifying if, where and how ecosystem vulnerability is affected by human or natural disturbances (Linder et al., 2010; Chmura et al., 2011). However, subjective evaluation has been recognized to often overestimate or underestimate the environmental effects (Basso et al., 2000). In the past decades, many methods have been proposed to evaluate the eco-environmental effects, such as the fuzzy evaluation (Adriaenssens et al., 2004), comprehensive evaluation (Goda and Matsuoka, 1986) and artificial neural-network evaluation methods, along with the grey evaluation method (Hao and Zhou, 2002; Park et al., 2004). However, the variables used in the above-mentioned methods are not always easy to acquire (Beisner et al., 2003; Folke et al., 2004) and most related studies focused on small-scale regions. Furthermore, the methods developed for small spatial scales have been confronted with serious criticisms when used at a regional or much larger level (Suter, 1993; Tran et al., 2002). Hence, regional environmental vulnerability assessment still remains a great challenge (Boughton et al., 1999).

Recently, space technologies, such as remote sensing (RS) and satellites have provided a powerful tool for environmental assessment on a macroscopic scale (Beisner et al., 2003; Krivtsov, 2004). Integration of these space-based technologies can not only supply a platform to support multi-level analysis on resource and environment but also integrate the obtained information into a comparative theoretical ecosystem analysis ( $\mathrm{Li}$ et al., 2006).

The major objective of this study was to analyze the spatial patterns of ecosystem vulnerability changes in the TRSR of the Qinghai-Tibetan Plateau, China. We introduced many interdisciplinary factors, such as landscape pattern indices and extreme climate factors to establish a new evaluation system. This study integrated the analytic hierarchy process (AHP) and comprehensive index methods to build an ecosystem vulnerability index (ESVI) model for obtaining the vulnerability evaluation of the TRSR. Then, the spatial distributions of ecosystem vulnerability changes were analyzed, and the driving forces of the changes were discussed. The results can provide basic ecological and environmental background information for the environmental restoration and protection in the TRSR.

\section{Materials and methods}

\subsection{Study area}

The three-river source region (TRSR; $31^{\circ} 39^{\prime \prime}-36^{\circ} 12^{\prime \prime} \mathrm{N}, 89^{\circ} 45^{\prime \prime}-102^{\circ} 23^{\prime \prime} \mathrm{E}$ ), located in the west of China with a total area of $361,200 \mathrm{~km}^{2}$, refers to the source regions of the Yangtze, Yellow and Lancang rivers in the Qinghai-Tibetan Plateau (Fig. 1). Within the TRSR, the Yangtze, Yellow and Lancang rivers are 1,217, 1,959 and $448 \mathrm{~km}$ long, respectively. Most of the region are at least $4,000 \mathrm{~m}$ in altitude and are characterized by low temperature with the annual average temperature from $-5.4^{\circ} \mathrm{C}$ to $4.2^{\circ} \mathrm{C}$ in different regions. The annual precipitation decreases from $770 \mathrm{~mm}$ in the southeast to $260 \mathrm{~mm}$ in the northwest, with approximately $70 \%$ of the total precipitation occurring from June to September. The vegetation cover gradually decreases from 
the southeast to the northwest. As a typical permafrost region, the TRSR is more sensitive to climatic warming and human disturbance (Wang et al., 2009). The major vegetation types in the TRSR are alpine grassland, alpine steppe, alpine shrubs and alpine forests. The combination of the above-mentioned features determines the facts that TRSR is a unique region, and evaluating its ecosystem vulnerability is urgent to protect the TRSR in the future.

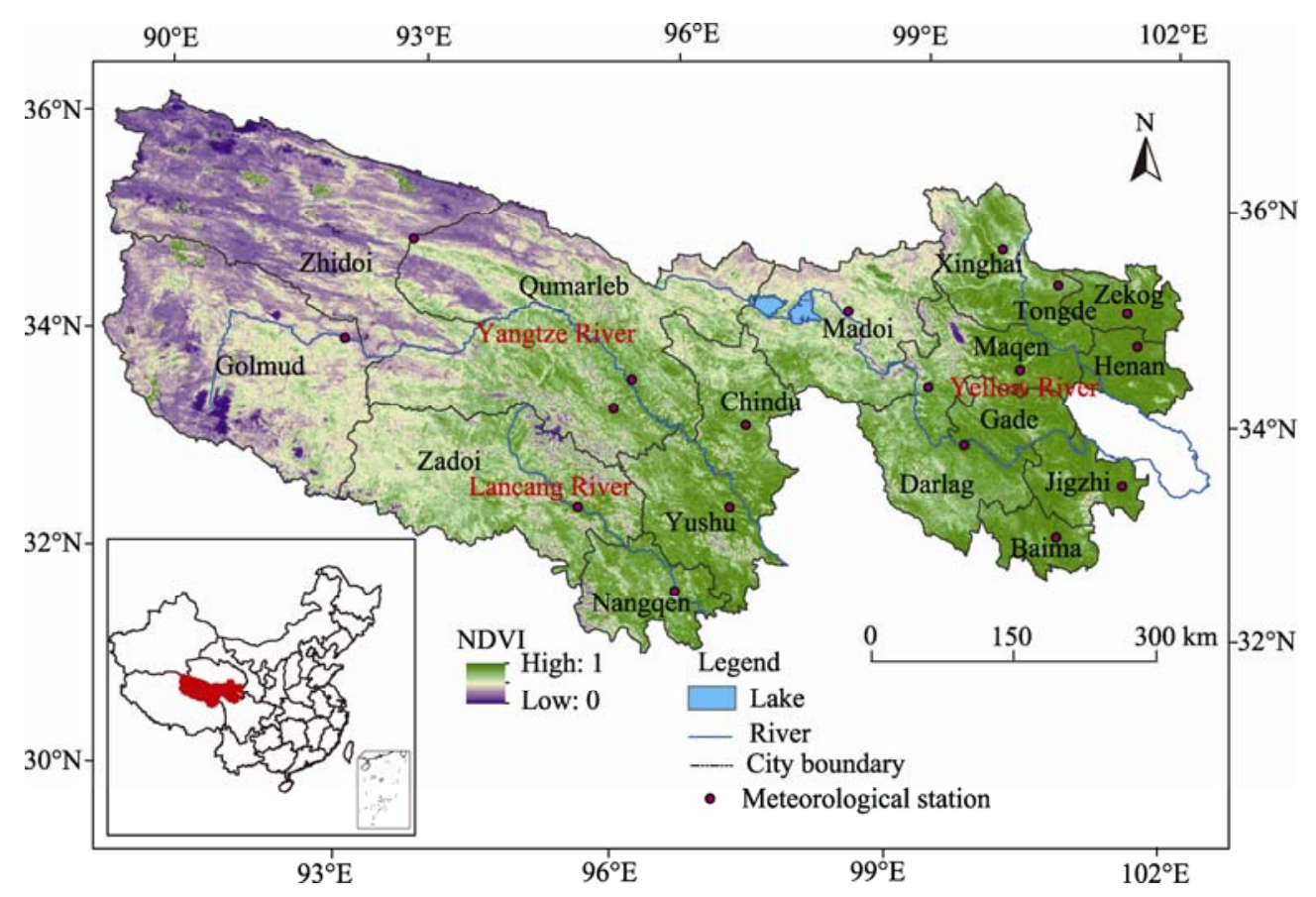

Fig. 1 Distribution of average normalised difference vegetation index (NDVI) in the growing seasons for 2001-2011 and the locations of meteorological stations in the three-river source region (TRSR)

\subsection{Data collection and processing}

The data used in this study included: (1) RS data, including the normalized difference vegetation index (NDVI) of the Moderate Resolution Imaging Spectroradiometer (MOD13Q1; in July 2001 and July 2011), net primary production (NPP) of MOD17A3 (in 2001 and 2011) and land cover type of MOD12Q1 (in 2001 and 2011); (2) data of soil type, obtained from the Institute of Soil Science, Chinese Academy of Sciences; (3) data of the 90-m Digital Elevation Model (available at http://datamirror.csdb.cn) obtained from the National Geospatial-Intelligence Agency and National Aeronautics and Space Administration; (4) meteorological data of water and heat (in 2001 and 2011) obtained from the Chinese Environmental Background Database; (5) socio-economic data from the annual statistics of Qinghai province; (6) amount of water resources (AWR) data acquired from the Ministry of Environmental Protection of the People's Republic of China; and (7) soil erosion and salinization data from the Institute of Remote Sensing and Digital Earth, Chinese Academy of Sciences.

We adopted the next three steps to further process the source data. (1) The water channel density (WCD), biologic abundance index (BAI) and landscape pattern indices (Shannon diversity index (SHDI) and Shannon evenness index (SHEI)) were generated from the data of land cover type using the ArcGIS 10.1 and Fragstats 3.4 tools. Climate data included accumulated temperature of $\geq 10^{\circ} \mathrm{C}$ (AT $\left(\geq 10^{\circ} \mathrm{C}\right)$ ), average annual precipitation (AAP), air humidity $(\mathrm{AH})$, and extreme climate data (number of extreme high temperature days (NEHTD), number of extreme low temperature days (NELTD) and number of extreme precipitation days (NEPD)); and anthropogenic factors included population density (PD), gross domestic product density (GDPD), Engle's Coefficient (EC) and per capita net income of farmers and herdsmen (PCNIFH). (2) Unified the geo-reference of all factors. The coordinate system was the Albers Equal Area System with original longitude of $105^{\circ} \mathrm{E}$, original 
latitude of $0^{\circ} \mathrm{N}$, double-standard parallel of $25^{\circ} \mathrm{N}$ and $47^{\circ} \mathrm{N}$ and D_Krasovsky_1940 datum. (3) Made a grid of the vector data. All the gridded images were at a spatial resolution of $1,000 \mathrm{~m}$.

\subsection{Factors influencing the eco-environment}

Selection of the evaluation criteria is significantly important in a regional assessment. The selected evaluation factors should be indicative, operational and representative (Alewell and Manderscheid, 1998). Because of the high altitude and terrain features of the region, the mean air temperature is below $-1{ }^{\circ} \mathrm{C}$ and the annual precipitation is approximately $470 \mathrm{~mm}$. Furthermore, the climate of the study region in winter is significantly affected by the cold current of the Mongolia-Siberian system. This region is characterized by loose soil surface, widely distributed deserts, strong wind and low vegetation cover. In recent decades, climate warming has modified the disturbance regimes of the ecosystem by altering the frequency, duration and intensity of extreme climate events. Along with the reduced precipitation and rising temperature, human activities such as deforestation and overgrazing have also exerted substantial influence on the eco-environment (Linder et al., 2010). These activities decreased the vegetation cover and destroyed the physical and chemical structures of the topsoil. Both natural and anthropogenic factors could exacerbate the ecosystem vulnerability of the TRSR.

Based on the unique conditions and some previous qualitative analyses of the environmental features in the TRSR (Yang et al., 2004; Zhang and Wu, 2012), we considered all the possible environmental factors for the present evaluation. Then, we finally chose 16 factors to establish the evaluation index system by performing a covariance analysis among the factors (Table 1).

Table 1 Factors used for assessing the ecosystem vulnerability in the TRSR

\begin{tabular}{|c|c|c|c|}
\hline Group & Factor & Definition and major impact on eco-environment & Data acquisition \\
\hline $\begin{array}{l}\text { Water } \\
\text { resources }\end{array}$ & $\begin{array}{l}\text { AWR } \\
\text { WCD }\end{array}$ & $\begin{array}{l}\text { The rivers are impacted by human activities and } \\
\text { then strongly influence the plant growth }\end{array}$ & $\begin{array}{l}\text { Interpreted from Landsat TM images } \\
\text { Observed and calculated data from } \\
\text { hydrological stations }\end{array}$ \\
\hline \multirow[t]{2}{*}{ Vegetation } & $\begin{array}{l}\text { BAI } \\
\text { NPP }\end{array}$ & $\begin{array}{l}\text { Vegetation cover/biomass and biodiversity over } \\
\text { land surfaces }\end{array}$ & $\begin{array}{l}\text { Calculated data from land-use types } \\
\text { Data obtained from MOD17A3 }\end{array}$ \\
\hline & $\begin{array}{l}\text { SHEI } \\
\text { SHDI }\end{array}$ & \multirow{2}{*}{$\begin{array}{l}\text { Landscape patterns can largely indicate the } \\
\text { conditions of the ecosystem and are impacted by } \\
\text { human disturbances } \\
\text { Average annual precipitation can influence the } \\
\text { spatial distribution of plants }\end{array}$} & $\begin{array}{l}\text { Calculated data from land-use types } \\
\text { Calculated data from land-use types }\end{array}$ \\
\hline \multirow[t]{8}{*}{ Climate } & AAP & & \\
\hline & $\begin{array}{c}\mathrm{AT} \\
\left(\geq 10^{\circ} \mathrm{C}\right)\end{array}$ & Strongly influences plant growth & \\
\hline & $\begin{array}{l}\mathrm{NDWV} \\
(\geq 6 \mathrm{~m} / \mathrm{s})\end{array}$ & $\begin{array}{l}\text { Number of days with wind velocity } \geq 6 \mathrm{~m} / \mathrm{s} \text {, which } \\
\text { strongly influences soil erosion and moisture }\end{array}$ & $\begin{array}{l}\text { Observed and calculated data from } \\
\text { meteorological stations }\end{array}$ \\
\hline & $\mathrm{AH}$ & Strongly influences plant growth and soil moisture & \\
\hline & $\mathrm{SH}$ & $\begin{array}{l}\text { Sunshine hour can strongly influence the plant } \\
\text { growth }\end{array}$ & \\
\hline & NEHTD & \multirow{3}{*}{$\begin{array}{l}\text { Extreme climate events, which can significantly } \\
\text { indicate the influence brought by the climate } \\
\text { warming on the ecosystem }\end{array}$} & \multirow{3}{*}{$\begin{array}{l}\text { Observed and calculated data from } \\
\text { meteorological stations }\end{array}$} \\
\hline & NELTD & & \\
\hline & NEPD & & \\
\hline \multirow[t]{3}{*}{ Soil } & SWE & \multirow{3}{*}{$\begin{array}{l}\text { These three factors can better reflect the } \\
\text { relationship between natural and socio-economic } \\
\text { systems }\end{array}$} & Obtained data from the Institute of \\
\hline & SFTE & & Remote Sensing and Digital Earth, \\
\hline & SSA & & Chinese Academy of Sciences \\
\hline \multirow{4}{*}{$\begin{array}{l}\text { Human } \\
\text { activities }\end{array}$} & PD & \multirow{4}{*}{$\begin{array}{l}\text { These two factors can reflect the development } \\
\text { intensity }\end{array}$} & \multirow{4}{*}{$\begin{array}{l}\text { Obtained data from statistical data of } \\
\text { provinces (Hao and Zhou, 2002) }\end{array}$} \\
\hline & GDPD & & \\
\hline & $\mathrm{EC}$ & & \\
\hline & PCNIFH & & \\
\hline
\end{tabular}

Note: AWR, amount of water resources; WCD, water channel density; BAI, biological abundance index; NPP, net primary production; SHEI, Shannon evenness index; SHDI, Shannon diversity index; AAP, average annual precipitation; AT ( $\left.\geq 10^{\circ} \mathrm{C}\right)$, accumulative temperature of $\geq 10^{\circ} \mathrm{C}$; NDWV ( $\geq 6 \mathrm{~m} / \mathrm{s}$ ), number of days with wind velocity $\geq 6 \mathrm{~m} / \mathrm{s}$; AH, air humidity; SH, sunshine hour; NEHTD, number of extreme high temperature days; NELTD, number of extreme low temperature days; NEPD, number of extreme precipitation days; SWE, soil water erosion; SFTE, soil freeze-thaw erosion; SSA, soil salinization; PD, population density; GDPD, gross domestic product density; EC, Engle's Coefficient; PCNIFH, per capita net income of farmers and herdsmen. The meanings of the abbreviations are the same as in Table 4. 
Because the factors were measured in different units of the measurement, standardization was needed to eliminate the unit difference among variables. The variables can be standardized using Eqs. 1 and 2.

Positive factor: $I_{i j}=\frac{x_{i j}-x_{\min , j}}{x_{\max , j}-x_{\min , j}}, \quad(1) ; \quad$ Negative factor: $I_{i j}=\frac{x_{\max , j}-x_{i j}}{x_{\max , j}-x_{\min , j}}$.

Where, $I_{i j}$ represents the standardized value of grid $i$ in factor $j ; x_{i j}$ is the original value of grid $i$ in factor $j$; and $x_{\max , j}$ and $x_{\min , j}$ represent the maximum and minimum values of factor $j$, respectively.

\subsection{Weights of factors}

Another important issue for the evaluation was to assign a weight to each factor according to its relative effects on the eco-environmental vulnerability. AHP (Suter, 1993) is an appropriate method to derive the weight of each factor. AHP has been widely applied in environmental evaluation and regional sustainable management (Bantayan and Bishop, 1998). In this study, the process of obtaining the weight of each factor is listed in Tables 2-4.

Table 2 Scale of binary comparison

\begin{tabular}{ll}
\hline Degree of importance & Definition \\
\hline 1 & Equal importance of two elements \\
3 & Weak importance of an element compared with another one \\
5 & Strong importance of an element compared with another one \\
7 & Very strong importance of an element compared with another one \\
9 & Absolute importance of an element compared with another one \\
$2,4,6,8$ & Intermediate values between two appreciations \\
$1 / 2,1 / 3,1 / 4,1 / 5,1 / 6,1 / 7,1 / 8,1 / 9$ & Reciprocal values of the previous appreciations \\
\hline
\end{tabular}

Table 3 Relative weights of the second grade factors of vulnerability evaluation for analytic hierarchy process

\begin{tabular}{lccccc}
\hline Evaluation index & Water resources & Vegetation & Climate & Soil & Human activities \\
\hline Water resources & 1 & & & & \\
Vegetation & $1 / 2$ & 1 & & & \\
Climate & 1 & 2 & 1 & 1 & 1 \\
Soil & 2 & 3 & $1 / 3$ & $1 / 3$ & 1 \\
Human activities & $1 / 2$ & $1 / 2$ & & \\
\hline
\end{tabular}

\subsection{ESVI calculation}

The evaluation of ecosystem vulnerability requires the integration of multiple factors for obtaining a comprehensive evaluation index. Thus, we adopted the method of weighted linear combinations to calculate the ESVI (Eq. 3).

$$
\operatorname{ESVI}=\left(\sum_{i=1}^{n} W_{i} I_{i}\right) /\left(\sum_{i=1}^{n} W_{i}\right)
$$

Where, $W_{i}$ is the weight of factor $i$ and $I_{i}$ is the value of factor $i$.

\subsection{Classification of ecosystem vulnerability}

The results obtained from the ESVI model were continuous values, which could be classified into different levels to represent the ecosystem vulnerability. Classification is very important in the evaluation of ecosystem vulnerability; therefore, it should be objective and logical.

The natural break classification (NBC) method is a graphical tool to analyze and explore the statistical distribution of classes and clusters in an attribute space ( $\mathrm{Li}$ et al., 2006). Because 
different classes are based on inherent natural grouping, NBC can identify break points by picking the class breaks that group similar values and maximize the differences among classes. Finally, the continuous values were divided into different classes whose boundaries were set where relatively big lumps in the data values existed.

Thus, we adopted the natural breaks of ArcGIS 10.1, which combined the histogram and cluster methods, to classify the ecosystem vulnerability into five levels. To confirm the objective of the threshold value for each vulnerability level, we then utilized the annual average NDVI to test and modify the threshold values. The five categories were defined as slight (ESVI $<0.62)$, mild $(0.62 \leq \mathrm{ESVI}<0.73)$, moderate $(0.73 \leq \mathrm{ESVI}<0.80)$, intensive $(0.80 \leq \mathrm{ESVI}<0.95)$ and severe (ESVI $\geq 0.95)$ vulnerabilities.

Table 4 Weights of the factors for ecosystem vulnerability evaluation for ecosystem vulnerability index (ESVI)

\begin{tabular}{|c|c|c|c|c|}
\hline First grade & Second grade & Weight & Third grade & Weight \\
\hline \multirow{21}{*}{ ESVI } & \multirow[t]{2}{*}{ Water resources } & \multirow[t]{2}{*}{0.207} & AWR & 0.104 \\
\hline & & & WCD & 0.104 \\
\hline & \multirow[t]{4}{*}{ Vegetation } & \multirow[t]{4}{*}{0.258} & BAI & 0.122 \\
\hline & & & NPP & 0.107 \\
\hline & & & SHEI & 0.014 \\
\hline & & & SHDI & 0.014 \\
\hline & \multirow[t]{8}{*}{ Climate } & \multirow[t]{8}{*}{0.126} & AAP & 0.024 \\
\hline & & & $\mathrm{AT}\left(\geq 10^{\circ} \mathrm{C}\right)$ & 0.019 \\
\hline & & & $\operatorname{NDWV}(\geq 6 \mathrm{~m} / \mathrm{s})$ & 0.024 \\
\hline & & & $\mathrm{AH}$ & 0.019 \\
\hline & & & NEHTD & 0.007 \\
\hline & & & NELTD & 0.011 \\
\hline & & & NEPD & 0.011 \\
\hline & & & SH & 0.011 \\
\hline & \multirow[t]{3}{*}{ Soil } & \multirow[t]{3}{*}{0.321} & SWE & 0.064 \\
\hline & & & SFTE & 0.161 \\
\hline & & & SSA & 0.096 \\
\hline & \multirow[t]{4}{*}{ Human activities } & \multirow[t]{4}{*}{0.088} & PD & 0.033 \\
\hline & & & GDPD & 0.033 \\
\hline & & & $\mathrm{EC}$ & 0.011 \\
\hline & & & PCNIFH & 0.011 \\
\hline
\end{tabular}

\subsection{Trend coefficients of climate factors}

Trend coefficient can demonstrate the change ratio and direction of the climate factors in a long-term period (Sun et al., 2007; Li and Zhang, 2011). An increasing trend occurs when the trend coefficient is positive; while a negative trend coefficient indicates a decreasing trend. Furthermore, the change ratios of the climate factors can be determined by the absolute value of the trend coefficient. The bigger the absolute value is, the larger is the change ratio of the climate factor. The absolute value of the trend coefficient can be expressed as Eq. 4.

$$
r_{x t}=\left|\frac{\sum_{i=1}^{n}\left(x_{i}-\bar{x}\right)(i-\bar{t})}{\sqrt{\sum_{i=1}^{n}\left(x_{i}-\bar{x}\right)^{2}(i-\bar{t})^{2}}}\right|
$$

Where, $r_{x t}$ is the absolute value of the trend coefficient; $n$ refers to the number of years; $x_{i}$ is the 
value of the climate factor in year $i ; \bar{x}$ refers to the average value of the climate factor; and $\bar{t}$ refers to the value of $(n+1) / 2$. The larger $r_{x t}$ is, the more dramatic is the change intensity (CI) of the climate factor.

\section{Results}

\subsection{Spatial patterns of ecosystem vulnerability in 2001 and 2011}

According to the standards mentioned above, we classified the evaluation indices of the comprehensive ecosystem vulnerability in 2001 and 2011 to generate the corresponding results (Fig. 2; Table 5).


Fig. 2 Distributions of ecosystem vulnerability in 2001 (a) and 2011 (b) in the study area

The vulnerable region was widely distributed in the TRSR (Fig. 2). The spatial disparities of the zones at different classifications differed significantly. The intensively and severely vulnerable zones were continuously distributed in the mid-western region, such as Zhidoi, Golmud, Zadoi and Qumarleb. The slightly and mildly vulnerable regions were discontinuously concentrated in the eastern part of the study area, including Baima, Henan, Gade and Zekog. From 2001 to 2011, the areas of intensive and severe ecosystem vulnerability increased by $5.21 \%$ and $2.05 \%$, respectively. Correspondingly, the areas of moderate, mild and slight ecosystem 
vulnerability decreased by $6.06 \%, 1.03 \%$ and $0.18 \%$, respectively. The average values of ESVI in 2001 and 2011 over the whole study region were 4.21 and 4.28, respectively. Figure 2 and Table 5 further showed a slight deterioration trend in the eco-environmental quality during 2001-2011, which was indicated by the enlarged zones of intensive and severe vulnerability.

Table 5 Area and area percentage of each ecosystem vulnerability level in 2001 and 2011 in the TRSR

\begin{tabular}{cccccc}
\hline \multirow{2}{*}{ Vulnerability level } & \multicolumn{2}{c}{2001} & & \multicolumn{2}{c}{2011} \\
\cline { 2 - 3 } \cline { 5 - 6 } & Area $\left(10^{4} \mathrm{~km}^{2}\right)$ & Percentage $(\%)$ & & Area $\left(10^{4} \mathrm{~km}^{2}\right)$ & Percentage $(\%)$ \\
\hline Slight & 1.79 & 5.14 & 6.08 & 1.72 & 4.96 \\
Mild & 2.11 & 30.13 & & 1.76 & 5.05 \\
Moderate & 10.48 & 48.99 & 8.37 & 24.07 \\
Intensive & 17.03 & 9.65 & 18.84 & 54.20 \\
Severe & 3.35 & & 4.07 & 11.72 \\
\hline
\end{tabular}

\subsection{Ecosystem vulnerability of the TRSR}

The ecosystem vulnerability significantly differed in different parts of the TRSR. The bigger the value of ESVI, the more serious the eco-environmental vulnerability. In 2001, the average values of ESVI for the source regions of Yellow, Yangtze and Lancang rivers were 3.88, 4.42 and 4.15, respectively. In 2001, the intensively vulnerable zone in the Yangtze River source region was the largest (accounting for $65 \%$ of the total area of the Yangtze River source region), while the intensively vulnerable zone in the Yellow River source region was the smallest (Fig. 3). Therefore, the vulnerability of the Yangtze River source region was the heaviest, and the vulnerability of the Yellow river source region was relatively lighter. Similarly, in 2011, the ecosystem condition of the Yangtze River source region was the worst, with the mean ESVI of 4.52; while the Yellow River source region had the best ecosystem quality, with the mean ESVI of 3.89. From 2001 to 2011, the area of moderately vulnerable zone in the Lancang River source region decreased by $10.04 \%$, while the area of intensively vulnerable zone increased by $11.27 \%$. Thus, the CI of the Lancang River source region was the largest during 2001-2011.

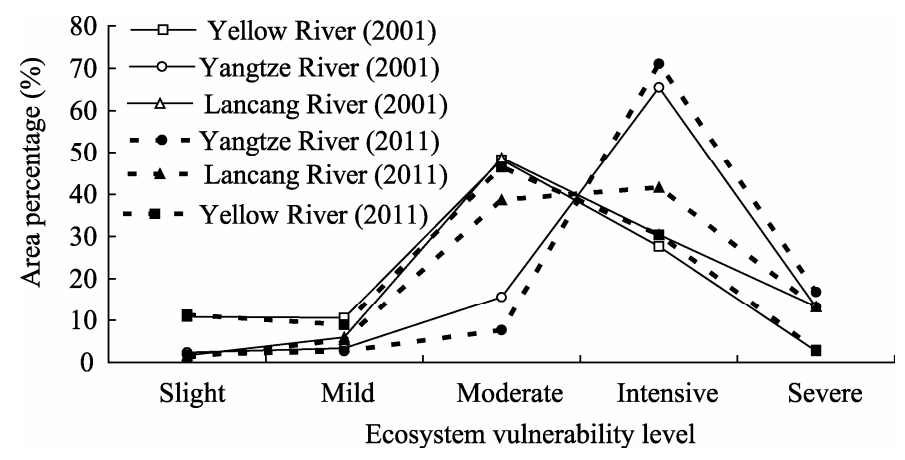

Fig. 3 Area percentage of each ecosystem vulnerability level in the source regions of Yangtze, Yellow and Lancang rivers in 2001 and 2011

\subsection{Change trend of ecosystem vulnerability}

To better monitor the changes in the ecosystem vulnerability during the study period, we obtained the CI of ecosystem vulnerability from 2001 to 2011 by the subtraction method using the raster calculator of ArcGIS 10.1.

According to the natural conditions of the study area, we divided the ESVI of the TRSR into five categories using the natural breaks of ArcGIS 10.1: severe decrease $(\mathrm{CI}<-0.5)$, mild decrease $(-0.5 \leq \mathrm{CI}<-0.25)$, stable $(-0.25 \leq \mathrm{CI}<0.25)$, mild increase $(0.25 \leq \mathrm{CI}<0.5)$ and severe increase $(\mathrm{CI} \geq 0.5)$.

The distribution of different CI grades of ecosystem vulnerability in the TRSR is shown in Fig. 4, 
which shows that the distinct spatial differentiation of ecosystem vulnerability exists for each CI grade during 2001-2011. The stable zone was most widely distributed, with an area of $23.09 \times 10^{4}$ $\mathrm{km}^{2}$. The zone with severe increase was discontinuously distributed in Madoi, Chindu, Zadoi and Qumarleb, with an area of $4.24 \times 10^{4} \mathrm{~km}^{2}$, accounting for $12.19 \%$ of the whole study area. The zone with mild increase was mainly concentrated in the west of the study region, such as Golmud and southern Zhidoi. Furthermore, the zones with mild and severe decreases were mainly distributed in the northeastern Zhidoi, Zekog, Tongde, Baima and Nangqen, accounting for approximately $11.31 \%$ of the whole study area. Thus, we concluded that during the study period (2001-2011), the ecosystem vulnerability over the whole TRSR was slightly intensive.

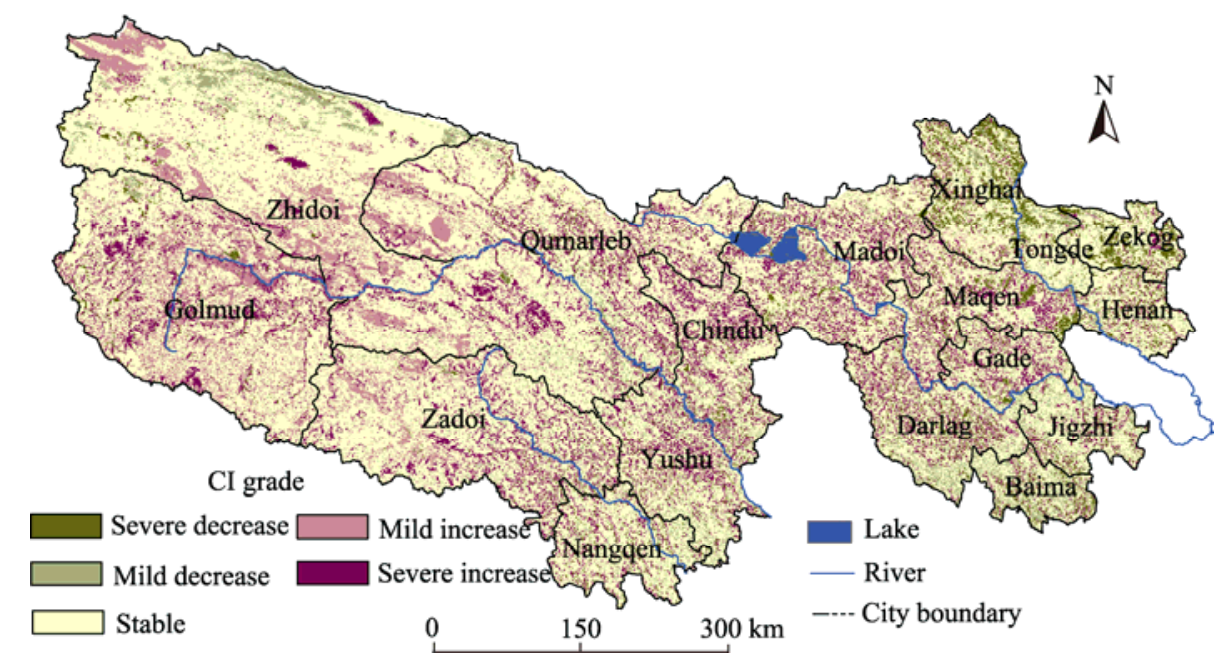

Fig. 4 Distribution of change intensity (CI) of ecosystem vulnerability from 2001 to 2011 in the TRSR

\section{Discussion}

\subsection{Accuracy assessment of the evaluation}

In general, the ecosystem vulnerability in the study area is at an intensive level because the moderately and intensively vulnerable zones occupied most of the study region (accounting for $78.27 \%$ ), which agrees with the results obtained by Kang et al. (2010). The study area is characterized by semi-arid and arid continental plateau climate with cold, dry and larger diurnal variation in temperature. The average annual precipitation is approximately $470 \mathrm{~mm}$. However, almost $70 \%$ of it occurs from June to September. Generally, soils are not developed well in this region, and the soil layer is thin with a depth of approximately $30-50 \mathrm{~cm}$ due to the effects of high elevation and cold weather (Liu et al., 2006). The water contention of soil during rainfall and snow melting periods in the TRSR has become larger with the exacerbation of global warming (Liu et al., 2009; Kang et al., 2010). The major vegetation types are alpine meadow and alpine grass. Thus, the vegetation cover is much lower. Moreover, climate change and human activities have resulted in the decrease in the grassland in some regions (Qian et al., 2010).

\subsection{Relationship between CI of ecosystem vulnerability and land-use types}

In this study, we chose seven typical land-use types (i.e. shrubs, deserts, steppe, water body, meadow, evergreen coniferous forests (ECF), and barren and sparse vegetation (BSV)) to analyze the correlation between the $\mathrm{CI}$ of ecosystem vulnerability and land-use types. A significant difference in CI of ecosystem vulnerability exists among all the land-use types (Fig. $5)$. The region dominated by deserts had the largest increased insensitive vulnerability with a mean CI value of 0.312 , which belongs to the grade of mild increase. This phenomenon resulted from the fact that the vegetation cover and gross primary productivity of the deserts were much lower; hence, the biodiversity was much smaller. Thus, the ecosystem of this region is more 
sensitive to climate change. During the past decades, the accelerated global warming has resulted in the increased temperature and decreased precipitation, which brought negative influences on the vegetation productivity and soil moisture (Roerink et al., 2003). Subsequently, the decrease in vegetation cover and soil moisture led to the deterioration of eco-environmental quality. The ecosystem vulnerability of the ECF decreased during the study period (the mean CI value of -0.09 ), because the zones occupied by ECF were concentrated in the east of the study area with abundant precipitation and water resources (Liu et al., 2009; Kang et al., 2010). Meanwhile, the mean values of CI for the shrubs as well as barren and sparse vegetation were higher $(0.089$ and 0.062 , respectively), because this two land-use types were mainly distributed in the mid-western part with low vegetation cover and scarce precipitation. Along with the decreased precipitation and increased temperature, the human activities, including deforestation, overgrazing and large-scale construction, exerted great influences on the eco-environment (Zhang et al., 2007). Both natural and anthropogenic factors could exacerbate the ecosystem vulnerability. The vulnerability of zones dominated by steppe, meadow and water body were stable, with the mean CI values of $0.055,0.056$ and 0.054 , respectively. These areas had abundant precipitation ranging from 300 to $600 \mathrm{~mm}$, and the vegetation cover was also high. However, the fluctuation range of ecosystem vulnerability was largest in the steppe among the three land-use types due to its wide distribution, followed by the meadow and water body. The zones dominated by shrubs were mainly concentrated in the middle of the TRSR. The ecological and environmental conditions of these areas greatly changed. Thus, by comparing the mean values and fluctuation ranges of the CI among all the land-use types, we can determine that during the study period, the zones dominated by deserts were the most severely deteriorated areas, followed by those dominated by shrubs. Furthermore, ecosystem conditions of the zones occupied by ECF had a better change.

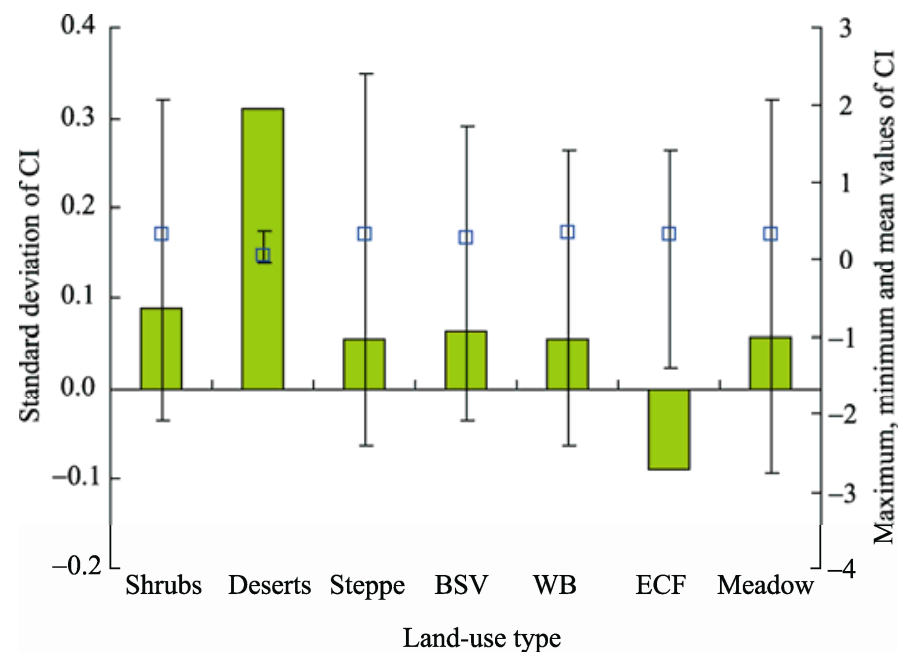

Fig. 5 Change intensity (CI) of ecosystem vulnerability for different land-use types in 2010. The top line shows the maximum value of CI for each land-use type, whereas the bottom line shows the minimum value. The green square refers to the mean value of CI, and the blue square refers to the standard deviation of CI. BSV, barren and sparse vegetation; WB, water body; ECF, evergreen coniferous forests.

\subsection{Relationship between the change of ecosystem vulnerability and climate factors}

Results of the ecosystem vulnerability and its changes in the TRSR showed that there was a slight degradation in the eco-environmental quality for the whole study area. In some regions, the ecosystem conditions had become worse from 2001 to 2011. Among all the factors, precipitation and temperature played important roles in affecting the eco-environment (Zhou et al., 2007). During the past decades, the accumulative temperature of $\geq 10^{\circ} \mathrm{C}$ in the TRSR showed an increasing trend, whereas the annual precipitation presented a decreasing trend (Zhou et al., 
2007). Vegetation cover showed a positive relationship with precipitation, while a negative correlation existed between the vegetation growth and accumulative temperature of $\geq 10^{\circ} \mathrm{C}$ (Zhou et al., 2007). Wang et al. (2009) pointed out that increases in air temperature and soil moisture would result in an increase in vegetation productivity, while decreases in air temperature and soil moisture would result in a decrease in vegetation productivity. Many studies found that ecosystem quality had a highly positive relationship with the NDVI and NPP (Isidori et al., 2004). Therefore, a decrease in vegetation cover would certainly lead to the increase of ecosystem vulnerability. Furthermore, the rise in temperature would increase evapotranspiration and therefore increase the loss of soil water. Thus, temperature had a negative correlation with ecosystem quality. Moreover, the water content of topsoil layer would increase when the temperature rises. Subsequently, the process of soil freeze-thaw erosion would be exacerbated by the increased water content in the shallow soil layer during the thawing period in cold regions.

To better understand how the change of ecosystem vulnerability was affected by the climate factors, we conducted an analysis on the relationship between CI and trend coefficients (Eq. 4) of annual precipitation and accumulative temperature of $\geq 10^{\circ} \mathrm{C}$ based on the data from 13 meteorological stations. A negative relationship existed between CI and trend coefficient of annual precipitation until the coefficient reached 0.25 (Fig. 6). Similarly, the CI of ecosystem vulnerability had a negative correlation with the trend coefficient of accumulative temperature of $\geq 10^{\circ} \mathrm{C}$ before the coefficient reached 0.7 . We thus concluded that annual precipitation and accumulative temperature of $\geq 10^{\circ} \mathrm{C}$ had a negative influence on the CI of ecosystem vulnerability when the change rate was low. However, if the change rate of the above-mentioned climate factors exceeds a certain value, they would aggravate the CI of ecosystem vulnerability.
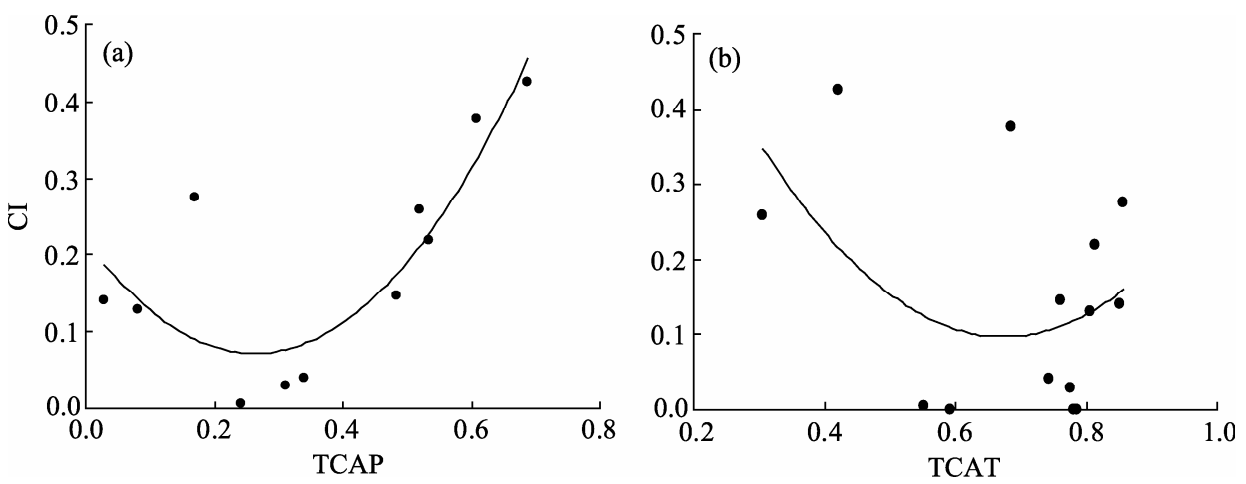

Fig. 6 Relationships of the CI of ecosystem vulnerability with (a) trend coefficient of annual precipitation (TCAP) and (b) trend coefficient of accumulative temperature of $\geq 10^{\circ} \mathrm{C}$ (TCAT)

\section{Conclusions}

In this study, we introduced many indices (e.g. SHEI, SHDI, NEHTD, NELTD and NEPD) to establish a new evaluation model for the estimation of ecosystem vulnerability in the TRSR. From this study, we can draw the following conclusions.

(1) This study demonstrated that the proposed model is an effective approach to estimate the ecosystem vulnerability with great applicability and practicability, because the obtained results reflect the reality of the eco-environmental vulnerability in the TRSR.

(2) The ecosystem vulnerability in the whole study area was intensive. Moreover, a slight deterioration of environmental quality occurred from 2001 to 2011. Among the source regions of the three rivers (Yangtze, Yellow and Lancang rivers), the source region of Yangtze River had the worst eco-environmental quality, while the ecosystem condition of Yellow River was the best. Furthermore, during the study period, the zones dominated by deserts were the most severely deteriorated areas, followed by those dominated by shrubs. Moreover, the eco-environment quality of the zones occupied by ECF showed a better change. These results 
suggested that specific environmental protection measures should be conducted in different regions with different ecosystem vulnerabilities. Furthermore, the larger the change rates of climate factors, the more intensive the CI of ecosystem vulnerability.

However, the new ESVI model still requires development to further reduce subjectivity in judgments, and further studies should be conducted to clarify the driving force mechanisms of changes in ecosystem vulnerability.

\section{Acknowledgements}

This study was supported by the Foundation of Director of Institute of Remote Sensing and Digital Earth, Chinese Academy of Sciences (Y4SY0200CX) and the Special Project on High Resolution of Earth Observation System for Major Function Oriented Zones Planning (00-Y30B14-9001-14/16).

\section{References}

Adriaenssens V, De Baets B, Goethals P L M, et al. 2004. Fuzzy rule-based models for decision support in ecosystem management. Science of the Total Environment, 319(1-3): 1-12.

Alewell C, Manderscheid B. 1998. Use of objective criteria for the assessment of biogeochemical ecosystem models. Ecological Modelling, 107(2-3): 213-224.

Bantayan N C, Bishop I D. 1998. Linking objective and subjective modelling for landuse decision-making. Landscape and Urban Planning, 43(1-3): 35-48.

Basso F, Bove E, Dumontet S, et al. 2000. Evaluating environmental sensitivity at the basin scale through the use of geographic information systems and remotely sensed data: an example covering the Agri basin (Southern Italy). Catena, 40(1): 19-35.

Beisner B E, Haydon D T, Cuddington K. 2003. Alternative stable states in ecology. Frontiers in Ecology and the Environment, 1(7): 376-382.

Boughton D A, Smith E R, O’Neill R V. 1999. Regional vulnerability: a conceptual framework. Ecosystem Health, 5(4): 312-322.

Chapin F S, Mcguire A D, Randerson J, et al. 2000. Arctic and boreal ecosystems of western North America as components of the climate system. Global Change Biology, 6(S1): 211-223.

Chmura D J, Anderson P D, Howe G T, et al. 2011. Forest responses to climate change in the northwestern United States: Ecophysiological foundations for adaptive management. Forest Ecology and Management, 261(7): 1121-1142.

Eisele M, Steinbrich A, Hidebrand A, et al. 2003. The significance of hydrological criteria for the assessment of the ecological quality in river basins. Physics and Chemistry of the Earth, Parts A/B/C, 28(12-13): 529-536.

Folke C, Carpenter S, Walker B, et al. 2004. Regime shifts, resilience, and biodiversity in ecosystem management. Annual Review of Ecology, Evolution, and Systematics, 35(1): 557-581.

Fu X F, Yang S T, Liu C M. 2007. Changes of NDVI and their relations with principal climatic factors in the Yarlung Zangbo River Basin. Geographical Research, 26(1): 60-66. (in Chinese)

Goda T, Matsuoka Y. 1986. Synthesis and analysis of a comprehensive lake model-with the evaluation of diversity of ecosystems. Ecological Modelling, 31(1-4): 11-32.

Goetz S J, Bunn A G, Fiske G J, et al. 2005. Satellite-observed photosynthetic trends across boreal North America associated with climate and fire disturbance. Proceedings of the National Academies of Sciences of the United States of America, 102(38): 13521-13525.

Guo Z R, Jing E C, Nie Z L, et al. 2002. Analysis on the characteristics of soil moisture transfer during freezing and thawing period. Advances in Water Science, 13(3): 298-302. (in Chinese)

Hao Y H, Zhou H C. 2002. A grey assessment model of regional eco-environment quality and its application. Environmental Engineering, 20(4): 66-68. (in Chinese)

IPCC. 2007. Climate Change 2007: The Physical Science Basis. Contribution of Working Group I to the Fourth Assessment Report of the Intergovernmental Panel on Climate Change. Cambridge: Cambridge University Press.

Isidori M, Lavorgna M, Nardelli A, et al. 2004. Integrated environmental assessment of Volturno River in South Italy. Science of the Total Environment, 327(1-3): 123-134.

Kang S C, Xu Y W, You Q L, et al. 2010. Review of climate and cryospheric change in the Tibetan Plateau. Environmental Research Letters, 5(1): 015101, doi: 10.1088/1748-9326/5/1/015101.

Krivtsov V. 2004. Investigations of indirect relationships in ecology and environmental sciences: a review and the implications for comparative theoretical ecosystem analysis. Ecological Modelling, 174(1-2): 37-54. 
Li A N, Wang A S, Liang S L, et al. 2006. Eco-environmental vulnerability evaluation in mountainous region using remote sensing and GIS: A case study in the upper reaches of Minjiang River, China. Ecological Modelling, 192(1-2): 175-187.

Li C L, Kang S C. 2006. Review of studies in climate change over the Tibetan Plateau. Acta Geographica Sinica, 61(3): 327-335. (in Chinese)

Li J L, Zhang W Y. 2011. A semiparametric threshold model for censored longitudinal data analysis. Journal of the American Statistical Association, 106(494): 685-696.

Linder M, Maroschek M, Netherer S, et al. 2010. Climate change impacts, adaptive capacity, and vulnerability of European forest ecosystems. Forest Ecology and Management, 259(4): 698-709.

Liu J Y, Xu X L, Shao Q Q. 2008. Grassland degradation in the "Three-River Headwaters” region, Qinghai Province. Journal of Geographical Sciences, 18(3): 259-273.

Liu L S, Zhang Y L, Bai W Q, et al. 2006. Characteristics of grassland degradation and driving forces in the source region of the Yellow River from 1985 to 2000. Journal of Geographical Sciences, 16(2): 131-142.

Liu X D, Cheng Z G, Yan L B, et al. 2009. Elevation dependency of recent and future minimum surface air temperature trends in the Tibetan Plateau and its surroundings. Global and Planetary Change, 68(3): 164-174.

Ng K L, Obbard J P. 2005. Strategic environmental assessment in Hong Kong. Environment International, 31(4): $483-492$.

Park Y S, Chon T S, Kwak I S, et al. 2004. Hierarchical community classification and assessment of aquatic ecosystems using artificial neural networks. Science of the Total Environment, 327(1-3): 105-122.

Popp J H, Hyatt D E, Hoag D. 2000. Modeling environmental condition with indices: a case study of sustainability and soil resources. Ecological Modelling, 130(1-3): 131-143.

Qian S, Fu Y, Pan F F. 2010. Climate change tendency and grassland vegetation response during the growth season in Three-River Source Region. Science China Earth Sciences, 53(10): 1506-1512.

Roerink G J, Menenti M, Soepboer W, et al. 2003. Assessment of climate impact on vegetation dynamics by using remote sensing. Physics and Chemistry of the Earth, Parts A/B/C, 28(1-3): 103-109.

Sun Y, Zhang W Y, Tong H. 2007. Estimation of the covariance matrix of random effects in longitudinal studies. The Annals of Statistics, 35(6): 2795-2814.

Suter G W. 1993. A critique of ecosystem health concepts and indexes. Environmental Toxicology and Chemistry, 12(9): 1533-1539.

Tran L T, Knight C G, O’Neill R V, et al. 2002. Fuzzy decision analysis for integrated environmental vulnerability assessment of the Mid-Atlantic region. Environmental Management, 29(6): 845-859.

Wang G X, Hu H C, Li T B. 2009. The influence of freeze-thaw cycles of active soil layer on surface runoff in a permafrost watershed. Journal of Hydrology, 375(3-4): 438-449.

Wang Z L, Fu Q, Jiang Q X, et al. 2011. Numerical simulation of water-heat coupled movements in seasonal frozen soil. Mathematical and Computer Modelling, 54(3-4): 970-975.

Westerling A L, Turner M G, Smithwick E A H, et al. 2011. Continued warming could transform Greater Yellowstone fire regimes by mid- $21^{\text {st }}$ century. Proceedings of the National Academy of Sciences of the United States of America, 108(32): $13165-13170$.

Yang M X, Wang S L, Yao T D, et al. 2004. Desertification and its relationship with permafrost degradation in Qinghai-Xizang (Tibet) plateau. Cold Regions Science and Technology, 39(1): 47-53.

Zhang J G, Liu S Z, Yang S Q. 2007. The classification and assessment of freeze-thaw erosion in Tibet. Journal of Geographical Sciences, 17(2): 165-174.

Zhang Z Q, Wu Q B. 2012. Predicting changes of active layer thickness on the Qinghai-Tibet Plateau as climate warming. Journal of Glaciology and Geocryology, 34(3): 505-511. (in Chinese)

Zhou D W, Fan G Z, Huang R H, et al. 2007. Interannual variability of the normalized difference vegetation index on the Tibetan Plateau and its relationship with climate change. Advances in Atmospheric Sciences, 24(3): 474-484. 